\section{Effect of EDTA and QMIX Ultrasonic Activation on the Reduction of Microorganisms and Endotoxins in Ex Vivo Human Root Canals}

Felipe de Souza Matos ${ }^{1}{ }^{\circledR 0}$, Rayana Duarte Khoury ${ }^{1}{ }^{\circledR}$, Cláudio Antonio Talge

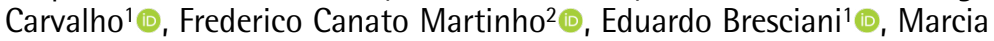
Carneiro Valera' ${ }^{10}$
'Department of Restorative Dentistry, Institute of Science and Technology, UNESP Universidade Estadual Paulista, São José dos Campos, SP, Brazil 2University of Maryland School of Dentistry, Baltimore, Maryland, USA

Correspondence: Marcia Carneiro Valera, Avenida Eng Francisco José Longo, 777, 12245-000 São José dos Campos, SP, Brasil. Tel: +55-12-3947-9050. e-mail address: marcia@ict.unesp.br
The present study aimed to compare the effectiveness of QMiX and 17\% EDTA associated to passive ultrasonic irrigation (PUI) or manual agitation (MA) on the reduction of $E$. faecalis, $E$. coli and LPS from root canals. Forty single rooted human teeth were randomly divided into four groups $(n=10)$, according to the final irrigation protocol: EDTA+MA, QMiX+MA, EDTA+PUI, $\mathrm{QMiX}+\mathrm{PUI}$. Sample collections were obtained from the root canal content immediately before preparation (baseline-S1), after instrumentation (S2), after final irrigation protocol (S3) and 7 days after instrumentation and final irrigation (S4). The antimicrobial effectivity and on endotoxin content were analyzed by culture procedure (CFU/mL) and LAL assay (EU/ $\mathrm{mL}$ ), respectively. The results were statistically analyzed by Kruskal-Wallis and Friedman test $(\alpha=5 \%)$. $\mathrm{QMiX}+\mathrm{MA}$ and $\mathrm{QMiX}+\mathrm{PUI}$ reduced $100 \%$ of $E$. coli and $E$. faecalis bacteria and also prevented $E$. faecalis regrowth at $S 4$. EDTA significantly reduced $E$. coli, but it was not effective in reducing $E$. faecalis. All protocols reduced $\mathrm{EU} / \mathrm{mL}$ when compared to $\mathrm{S} 1$, however at $\mathrm{S} 4$ there was a significant reduction of $\mathrm{EU} / \mathrm{mL}$ only in the $\mathrm{QMiX}+\mathrm{MA}$ and $\mathrm{QMiX}+\mathrm{PUI}$ groups in relation to S3 and S2, respectively. Final irrigation with $\mathrm{QMiX}$ associated with MA or PUI had superior antibacterial efficacy compared to EDTA, eliminating $100 \%$ of E. coli and E. faecalis strains. In addition, QMiX+PUI reduced $97.61 \%$ of the initial content of LPS.
Key Words: bacteria, endotoxin, passive ultrasonic irrigation, QMix root canal irrigant.

\section{Introduction}

The failure of root canal treatment has been mostly related to the remaining bacteria within the root canal system. Moreover, lipopolysacharide (LPS) is an endotoxin present in the cell walls of gram-negative bacteria and is usually detected in persistent root canal infections being correlated to the presence of symptoms and bone resorption. The ineffective removal of microorganisms and their virulence factors contributes to the maintenance of apical periodontitis (1). Therefore, an adequate elimination or reduction of bacteria and endotoxin removal/ neutralization during endodontic treatment seems to be essential for the healing process of periapical tissues of endodontic infections (2).

The effective debridement and disinfection can be attained by using irrigating solutions during the cleaning and shaping procedures. These solutions must be able to not only dissolve organic and inorganic components but also possess antimicrobial potential. No irrigating solution has been shown to present all these properties and thus the synergistical use/action of two or more solutions may be necessary. In addition, the use of agitation techniques such as passive ultrasonic irrigation (PUI) has been known to promote better removal of the smear layer in the apical and isthmus regions as it is demonstrated by many studies (3).
Currently, sodium hypochlorite $(\mathrm{NaOCl})$ is the most widely used root canal irrigant because of its tissue dissolution and antimicrobial properties. However, due to the hard-tissue debris accumulation during root canal instrumentation, a final rinse with 17\% ethylenediaminetetraacetic acid (EDTA) is also highly often recommended because of its capacity to dissolve the inorganic component of the smear layer (4).

QMiX (Dentsply Tulsa Dental Specialties, Johnson City, $T N$, USA) has been proposed as a promising irrigation agent to be used as a final rinse removing smear layer and also killing persistent bacteria in one single step. This irrigant is composed by a mixture of a bisbiguanide antimicrobial agent, a polyaminocarboxylic acid calcium-chelating agent, saline and a surfactant (5). This composition is supposed to synthesize the antimicrobial and substantivity properties of $2 \%$ chlorhexidine $(\mathrm{CHX})$ with the smear layer removal properties of EDTA (6).

Recent studies have shown the effectivity of QMiX against Enterococcus faecalis (6-10), which in turns has been frequently identified as one of the most commonly species detected from root canals submitted to retreatment, in cases of failed endodontic treatment and persistent infections (7). Furthermore, QMiX has also been shown to decrease LPS from Escherichia coli, a gram-negative bacteria commonly found in root canals with periapical 
lesions (11).

Studies have shown that PUI can improve root canal cleaning ability (3) and that QMiX is an agent for final irrigation with action potential in the cleaning and disinfection of root canals (6).

Accordingly, the rationale of the study was that the dental literature shows a lack of importance of final irrigation alternatives with antimicrobial activity and the effect of different agitation techniques in final rinse has not been well-elucidated. The present study was conducted to compare the effectiveness of QMiX and 17\% EDTA solutions associated or not to PUI in eliminating E. faecalis, E. coli and LPS from root canals.

\section{Material and Methods}

\section{Sample Size Estimation}

This study was approved by the local Institute Review Board (CAAE: 79730317.2.0000.0077). Sample size calculation was performed based on previous data in log referred to bacterial reduction (9) after root canal instrumentation and medication. For the calculation, the options power calculation, continuous outcome and equivalence trial, on the sealed envelope website, were used. Considering $\alpha$ at 0.05 and power at $80 \%$, standard deviation of the outcome as 0.31 (9) and the equivalence limit as 0.5 , a total of 9 specimens per group were required to detect differences greater than 0.5 among groups. Thus, forty single rooted human teeth extracted for periodontal reasons were used.

\section{Selection and Preparation of the Specimens}

The teeth were cleaned and stored in distilled water at $4{ }^{\circ} \mathrm{C}$ until use. All the teeth were evaluated radiographically to confirm the presence of a single and circular root canal, mature apex, and absence of any resorption or endodontic treatment. The crowns were abraded from the occlusal surface down using a diamond disk (Horico Dental Hopf, Ringleb \&t Co $\mathrm{GmbH} \&$ Cie, Berlin, Germany) until the rubber stop met the occlusal edge at $16.0 \pm 0.5 \mathrm{~mm}$ thus standardizing the length of each specimen. In order to standardize the apical diameter of the teeth selected, the full length of the root canals was instrumented up to a \#30 Kerr file (Dentsply Ind. Com. Ltda., Petropolis, RJ, Brazil), followed by irrigation with $3 \mathrm{~mL}$ saline solution after each instrumentation. Next, the canals were filled with 17\% EDTA (Biodinâmica, Ibiporã, PR, Brazil) for 3 min and irrigated with $10 \mathrm{~mL}$ of saline solution. The apical region of each tooth was sealed with light-cured composite resin (Z-100, $3 \mathrm{M}$, Saint Paul, MN, USA) and the roots were externally sealed with 2 layers of epoxy adhesive (Brascola, São Paulo, $\mathrm{SP}$, Brazil), except the cervical opening. The specimens were randomly placed into four 24-well plates (Easypath,
São Paulo, SP, Brazil), each containing ten specimens and representing one experimental group, as described below. Initially, the samples were stored in eppendorf tubes numerically identified from 1 to 40 . Then, the numbers were randomly sorted into the respective groups via the RANDOM.ORG sequence generator (www.random.org). The first ten numbers generated were allocated to the EDTA+MA group, then to the groups QMiX+MA, EDTA+PUI and $\mathrm{QMiX}+\mathrm{PUI}$, successively. All culture plates, teeth and other materials used in the present study were sterilized by gamma irradiation (Embrarad, Cotia, SP, Brazil) for elimination of preexisting endotoxins.

\section{Contamination of Specimens}

Initially, a suspension of 106 cells $/ \mathrm{mL}$ of E. coli species (ATCC 25922) was prepared. Next, $10 \mu \mathrm{L}$ of this E. coli suspension was inoculated into each root canal followed by $10 \mu \mathrm{L}$ of brain heart infusion (BHI) broth (Himedia Laboratories, Mumbai, India). A sterile cotton pellet was soaked in the culture medium and placed in the cervical third of the root canals. All specimens were stored in an incubator at $37^{\circ} \pm 1^{\circ} \mathrm{C}$ in humidified atmosphere. BHI broth was added to root canals every three days. After 7 days, 10 $\mu \mathrm{L}$ of $E$. faecalis suspension at $10^{6} \mathrm{cells} / \mathrm{mL}$ (ATCC 29212) and $10 \mu \mathrm{L}$ of BHI broth were added to the root canals prior to storage of all the specimens in incubator at $37 \pm 1{ }^{\circ} \mathrm{C}$ and humidified atmosphere for 21 days. BHI broth was added to fill up completely the root canal lumen every three days.

\section{Sample Collection}

Immediately before biomechanical preparation, an initial sample (S1) was collected from the root canal to confirm contamination and serve as the baseline. For microbiological culture and endotoxin sampling, sterile/ apyrogenic paper points (size \#25; Dentsply Maillefer, Ballaigues, Switzerland) were introduced into the full length of the canal, and retained in position for $60 \mathrm{~s}$. Immediately after, the paper point was transferred to pyrogen-free eppendorf tubes containing $1000 \mu \mathrm{L}$ of pyrogen-free saline solution. For endotoxin quantification, the samples were diluted in $1 / 10,1 / 100$ and $1 / 1000$ because of the sensitivity of the kinetic chromogenic limulus amebocyte lysate test (KOCL). After the first sampling (S1), the biomechanical instrumentation was performed with 1 single file (R40, 0.06 taper size \# 40 instrument) from the Reciproc System (VDW, Munich, Germany) adapted to an electric motor (VDW) in reciprocation movement. Instrumentation was performed according to the crown-down technique (ie, coronal, medium, and apical) $1 \mathrm{~mm}$ short of the root canal length and associated to irrigation of $5 \mathrm{~mL}$ of pyrogenfree saline solution for each third, totaling $15 \mathrm{~mL}$. After instrumentation, a second sampling (S2) was performed 
in the same standard way as previously described. Then, the specimens were divided into four experimental groups ( $n=10$ each) according to the final irrigation protocol used, manually agitation (MA) or PUI:

EDTA+MA. After the second sampling, the specimens of this group were flooded with $3 \mathrm{~mL}$ of $17 \%$ EDTA solution (Biodinâmica, lbiporã, PR, Brazil) during a 2-minute period being manually agitated with a \# 15 Kerr file (Dentsply Ind. Com. Ltda., Petropolis, RJ, Brazil) during the last 60 s. Finally, the root canals were irrigated with $5 \mathrm{~mL}$ of saline solution.

QMiX+MA. After the second sampling, the specimens of this group were flooded with $3 \mathrm{~mL}$ of QMiX (Dentsply Tulsa Dental Specialties, Johnson City, TN, USA) during a 2-min period being manually agitated with a \# 15 Kerr file (Dentsply Ind. Com. Ltda., Petropolis, RJ, Brazil) during the last $60 \mathrm{~s}$. Finally, the root canals were irrigated with $5 \mathrm{~mL}$ of saline solution.

EDTA+PUI. After the second sampling, the specimens of this group were flooded with $3 \mathrm{~mL}$ of 17\% EDTA solution (Biodinâmica) during a 2-m period being ultrasonically agitated during the last $60 \mathrm{~s}$ using Irrisonic tip (E1, Helse Dental Technology, SP, Brazil) that was inserted $2 \mathrm{~mm}$ short of the root canal length. The power setting of the ultrasonic device was 10\% (Jet Sonic Satelec, Gnatus, Ribeirão Preto, SP, Brazil). Finally, the root canals were irrigated with 5 $\mathrm{mL}$ of saline solution.

QMiX+PUI. After the second sampling, the specimens of this group were flooded with $3 \mathrm{~mL}$ of QMiX during a 2-minute period being ultrasonically agitated during the last $60 \mathrm{~s}$ using Irrisonic tip (E1, Helse Dental Technology, $\mathrm{SP}$, Brazil) that was inserted $2 \mathrm{~mm}$ short of the root canal length. The power setting of the ultrasonic device was 10\% (Jet Sonic Satelec, Gnatus, Ribeirão Preto, SP, Brazil). Finally, the root canals were irrigated with $5 \mathrm{~mL}$ of saline solution.

After final irrigation protocol of each group, a third sampling (S3) was performed in the same standard way as previously described, in order to determine the antimicrobial activity of each final irrigating solution, associated to MA or PUI.

To determine the residual antimicrobial activity of the irrigant solutions, the root canals were filled with saline solution and stored in an incubator at $37^{\circ} \pm 1^{\circ} \mathrm{C}$ for seven days. A final sampling (S4) was performed to determine the residual antimicrobial activity of the final irrigation protocols.

\section{Culture Procedure}

To evaluate the antimicrobial activity, $100 \mu \mathrm{L}$ aliquots of all samples collected were serial diluted at S1 (baseline samples), S2 (after instrumentation), S3 (after final irrigation protocol), and $\mathrm{S} 4$ (after 7 days of instrumentation) were seeded in Enterococcosel agar (Himedia Laboratories, Mumbai, India) for Enterococcus faecalis, and MacConkey agar (Himedia Laboratories, Mumbai, India) for Escherichia coli. Then, all microorganisms were incubated at $37^{\circ} \mathrm{C}$ for $24 \mathrm{~h}$, and the number of colony-forming units (CFU/mL) was counted.

\section{Quantification of Endotoxins (LPSs): Kinetic Chromogenic LAL Assay}

The kinetic chromogenic limulus amebocyte lysate assay (Lonza, Walkersville, MD, USA) was used for quantification of endotoxins. Escherichia coli endotoxin was used as standard. For the test, $100 \mu \mathrm{L}$ of the diluted root canal samples was added to 96-well plate to find the ideal concentration within the detection limits of the standard curve. The samples were run in duplicate. Standard curve was performed in order to determine the levels of endotoxins present in the root canal samples, according to the manufacturer instructions. A spike procedure was performed according to the manufacturer's instructions in order to avoid possible interferences of contaminants present in the root canal samples with the recovery of endotoxins by the LAL test. Thus, each sample duplicated in the 96-well apyrogenic plate (Easypath, Sao Paulo, SP, Brazil) was contaminated with a known concentration of endotoxin $(10 \mathrm{EU} / \mathrm{mL})$. The plate was incubated at $37 \pm 1^{\circ} \mathrm{C}$ for $10 \mathrm{~min}$ in a KineticQCL reader, which was coupled to a microcomputer with the WinKQCL software. Next, $100 \mu \mathrm{L}$ of chromogenic reagent was added to each well. After the beginning of the kinetic test, the software continuously monitored absorbance at $405 \mathrm{~nm}$ in each microplate well and automatically calculated the $\log / \log$ linear correlation between reaction time of each standard solution and corresponding endotoxin concentration. The results were submitted to the Friedman test, with a level of significance at $5 \%$. The efficacy of the final irrigation protocols was also compared by descriptive analysis in reduction percentage of cultivable bacteria or endotoxins.

\section{Results}

\section{Culturing Procedure}

At the baseline ( $\mathrm{S} 1)$, microorganisms were recovered from $100 \%$ of the contaminated root canals (40/40).

The results of the analysis (colony-forming units $/ \mathrm{mL}$ ) showed that the biomechanical procedure (S2) was effective in reducing the number of $\mathrm{CFU} / \mathrm{mL}$ of both microorganisms, with statistical difference being observed between S1 and S2 as shown in Table $1(p<0.001)$.

After final irrigation protocol (S3), there was a statistically significant difference in all groups for $E$. coli (Table 1) by comparing the number of cultivable bacteria found in S2 $(p<0.001)$. Regardless of the agitation technique, EDTA was not effective in reducing $E$. faecalis ( $p>0.05$ ) (Table 1). $\mathrm{OMiX}+\mathrm{MA}$ and $\mathrm{QMiX}+\mathrm{PUI}$ were able to completely eliminate both microorganisms in all of the root 
canals analyzed, as shown in Table $1(p<0.001)$.

After 7 days of root canal instrumentation and final irrigation protocol (S4), both $\mathrm{QMiX}+\mathrm{MA}$ and $\mathrm{QMiX}+\mathrm{PUI}$ were effective in preventing $E$. faecalis regrowth $(\mathrm{p}>0.05)$, but $E$. coli was still detected in root canal samples from all groups, as shown in Table $1(p<0.001)$.

\section{Quantification of Endotoxins (LPSS): Kinetic Chromogenic LAL Assay}

In the baseline samples (S1), LAL assay indicated that endotoxins were found in all specimens (40/40).

Biomechanical preparation (S2) significantly reduced the number of EU/mL in all groups, as shown in Table 2 $(\mathrm{p}<0.001)$.

At S3 (Table 2), a higher number of $\mathrm{EU} / \mathrm{mL}$ was found in all groups in relation to $\mathrm{S} 2$, but this increase did not differ statistically from the values found in S2 ( $>>0.05$ ).

After 7 days of root canal instrumentation and final irrigation protocol (S4), there was a significant reduction of $\mathrm{EU} / \mathrm{mL}$ only in the $\mathrm{QMiX}+\mathrm{MA}$ group in relation to $\mathrm{S} 3$ and in the QMiX+PUl group in relation to S2 $(p<0.001)$. However, the level of endotoxins found in the groups EDTA+MA and EDTA+PUI at S4 did not differ statistically from S2 or S3 ( $p>0.05$ ), as shown in Table 2.

Figure 1 shows the descriptive analysis of cultivable bacterial reduction percentages after final irrigation protocols (S3) in relation to postinstrumentation (S2). $\mathrm{QMiX}+\mathrm{MA}$ and $\mathrm{QMiX}+\mathrm{PUI}$ reduced $100 \%$ of $E$. coli and $E$. faecalis bacteria. EDTA+PUI was more effective than EDTA+MA in reducing the bacterial counts. The descriptive analysis of endotoxin reduction percentages 7 days after the final irrigation protocols (S4) in relation to the initial sampling (S1) in all groups is presented in Figure 2. QMiX+PUI was the most efficient in endotoxin removal (97.61\%), followed by EDTA+PUI (96.93\%), EDTA+MA (93.97\%) and
QMiX+MA (92.62\%).

\section{Discussion}

Endodontic treatment of necrotic pulp teeth should not only kill bacteria through the antimicrobial action of irrigating solutions, but also remove dead cells and their by-products from the root canal system in order to maintain the integrity of the periapical tissues or allow their repair (7).

Mechanical action of endodontic instruments is limited due to complex anatomy of root canals. Therefore, chemical solutions are necessary to eliminate bacteria and dissolve organic tissue from root canal system. Several irrigation solutions are used as an adjunct to the mechanical preparation and even though there is no consensus on which irrigant and concentration should be used, $\mathrm{NaOCl}$ is the most widely used irrigant in endodontics since its great antimicrobial activity, the property to dissolve both organic components and necrotic tissues, low cost and availability (12). After a mechanical instrumentation a chelating agent is recommended as a final rinse for the removal of smear layer and the $\mathrm{NaOCl}$ following EDTA procedure is the most

Table 2. Endotoxin concentration (median and ranging values in $\mathrm{EU} / \mathrm{mL}$ ) found in root canals at baseline samples (S1), after instrumentation (S2), after final irrigation protocol (S3), and after 7 days of instrumentation (S4)

\begin{tabular}{lccccc}
\hline Groups & $\mathrm{S} 1$ & $\mathrm{~S} 2$ & $\mathrm{~S} 3$ & $\mathrm{~S} 4$ & $\mathrm{p}$ \\
\hline \multirow{2}{*}{ EDTA+MA } & $220.7^{\mathrm{a}}$ & $16.5^{\mathrm{b}}$ & $20.3^{\mathrm{b}}$ & $13.3^{\mathrm{b}}$ & \multirow{2}{*}{$(102-405)$} \\
& $(7.1-35.6)$ & $(10.2-58)$ & $\left(7.2^{-54)}\right.$ & $<0.001$ \\
QMiX+MA & $154.5^{\mathrm{a}}$ & $7.8^{\mathrm{bc}}$ & $19.5^{\mathrm{b}}$ & $11.4^{\mathrm{c}}$ & \\
& $(40-412.5)$ & $(1.4-19)$ & $(4.5-33)$ & $(8.6-19.8)$ & $<0.001$ \\
EDTA+PUI & $130.5^{\mathrm{a}}$ & $3.6^{\mathrm{b}}$ & $3.7^{\mathrm{b}}$ & $4^{\mathrm{b}}$ & \\
& $(23.7-582.5)$ & $(2.2-11.3)$ & $(0.8-16.4)$ & $(1.5-17.2)$ & $<0.001$ \\
QMiX+PUI & $368.7^{\mathrm{a}}$ & $19.7^{\mathrm{b}}$ & $34.5^{\mathrm{bc}}$ & $8.8^{\mathrm{c}}$ & \\
& $(208-1620)$ & $(9.6-83.6)$ & $(1.3-146)$ & $(5.7-29.1)$ & $<0.001$ \\
\hline
\end{tabular}

Friedman test. Different letters indicate, in the line, statistically significant differences $(p<0.05)$.

Table 1. Median and range of E. coli and E. faecalis CFU/mL counts for all groups at baseline samples (S1), after instrumentation (S2), after final irrigation protocol (S3), and after 7 days of instrumentation (S4)

\begin{tabular}{|c|c|c|c|c|c|c|c|c|c|c|}
\hline \multirow{2}{*}{ Groups } & \multicolumn{4}{|c|}{ E. coli } & & \multicolumn{4}{|c|}{ E. faecalis } & \multirow{2}{*}{$\mathrm{p}$} \\
\hline & S1 & S2 & S3 & S4 & & S1 & S2 & S3 & S4 & \\
\hline EDTA+MA & $\begin{array}{c}5165^{a} \\
(244-266000)\end{array}$ & $\begin{array}{c}221.5^{b} \\
(70-636)\end{array}$ & $\begin{array}{c}32^{\mathrm{c}} \\
(0-35)\end{array}$ & $\begin{array}{c}1116^{\mathrm{d}} \\
(496-2400)\end{array}$ & $<0.001$ & $\begin{array}{c}9300^{\mathrm{a}} \\
(3200-204000)\end{array}$ & $\begin{array}{c}472^{\mathrm{bc}} \\
(176-1568)\end{array}$ & $\begin{array}{c}228^{c} \\
(109-604)\end{array}$ & $\begin{array}{c}968^{\mathrm{b}} \\
(468-1540)\end{array}$ & $<0.001$ \\
\hline $\mathrm{QMiX}+\mathrm{MA}$ & $\begin{array}{c}9400^{\mathrm{a}} \\
(640-116000)\end{array}$ & $\begin{array}{c}116^{\mathrm{b}} \\
(0-936)\end{array}$ & $\begin{array}{c}0^{c} \\
(0-0)\end{array}$ & $\begin{array}{c}570^{\mathrm{b}} \\
(6-1292)\end{array}$ & $<0,001$ & $\begin{array}{c}7000^{\mathrm{a}} \\
(1100-51000)\end{array}$ & $\begin{array}{c}200^{\mathrm{b}} \\
(9-888)\end{array}$ & $\begin{array}{c}0^{c} \\
(0-1)\end{array}$ & $\begin{array}{c}0^{c} \\
(0-5)\end{array}$ & $<0.001$ \\
\hline EDTA+PUI & $\begin{array}{c}105000^{\mathrm{a}} \\
(11000-260000)\end{array}$ & $\begin{array}{c}131^{\mathrm{b}} \\
(13-270)\end{array}$ & $\begin{array}{c}1^{c} \\
(0-3)\end{array}$ & $\begin{array}{c}978^{d} \\
(41-1520)\end{array}$ & $<0.001$ & $\begin{array}{c}7650^{\mathrm{a}} \\
(1500-34000)\end{array}$ & $\begin{array}{c}73.5^{b} \\
(2-512)\end{array}$ & $\begin{array}{c}16^{\mathrm{b}} \\
(0-532)\end{array}$ & $\begin{array}{c}688^{c} \\
(34-1072)\end{array}$ & $<0.001$ \\
\hline $\mathrm{QMiX}+\mathrm{PUI}$ & $\begin{array}{c}57000^{\mathrm{a}} \\
(1600-170000)\end{array}$ & $\begin{array}{c}1350^{\mathrm{b}} \\
(6-640)\end{array}$ & $\begin{array}{c}0^{c} \\
(0-0)\end{array}$ & $\begin{array}{c}165^{b} \\
(0-470)\end{array}$ & $<0.001$ & $\begin{array}{c}16500^{\mathrm{a}} \\
(3000-43000)\end{array}$ & $\begin{array}{c}188^{\mathrm{b}} \\
(9-876)\end{array}$ & $\begin{array}{c}0^{c} \\
(0-0)\end{array}$ & $\begin{array}{c}0^{c} \\
(0-0)\end{array}$ & $<0.001$ \\
\hline
\end{tabular}

Friedman test. Different letters indicate, in the line, statistically significant differences $(\mathrm{p}<0.05)$. 
commonly used final irrigation regimen in endodontic treatment (13). However, alternative irrigant regimens have been investigated, since the extrusion of $\mathrm{NaOCl}$ on vital tissues and periapical areas causes several complications particularly when special care is needed as it is in pediatric endodontic treatment. In addition, although more debris is removed by irrigation with EDTA followed by $\mathrm{NaOCl}$ than with EDTA alone it is demonstrated that final irrigation with $\mathrm{NaOCl}$ following EDTA causes more dentinal erosion (14).

Based on this assumption, the present work evaluated the effect of two final irrigating solutions (17\% EDTA and $\mathrm{QMiX}$ ) and two agitation techniques (MA and PUI) on the neutralization of E. faecalis, E. coli and endotoxins (LPS) in ex vivo root canals. Ideally, $\mathrm{NaOCl}$ should be used for effective removal of smear layer after instrumentation to mimic clinical scenario (13), however, we aimed to evaluate the elimination of bacteria present in the contaminated smear layer focusing on the final irrigation step and the use of $\mathrm{NaOCl}$ might mask the effect of tested solutions.

The method of culture that detects viable and cultivable bacteria was used for microbiological analysis and, for analysis of endotoxins was used the kinetic chromogenic LAL assay (KOCL test). The KOCL test is a widely used method

some studies have demonstrated the antimicrobial potential of QMiX in human root canals $(6-8,10,17)$, there are no reports of the synergistic effect of $\mathrm{QMiX}$ and passive ultrasonic irrigation on LPS. It was verified that soon after the instrumentation (S2) there was the greatest reduction of bacteria and endotoxins within the root canal as a result of the mechanical and flushing removal of infected dentin during shaping and irrigation. However, a large number of

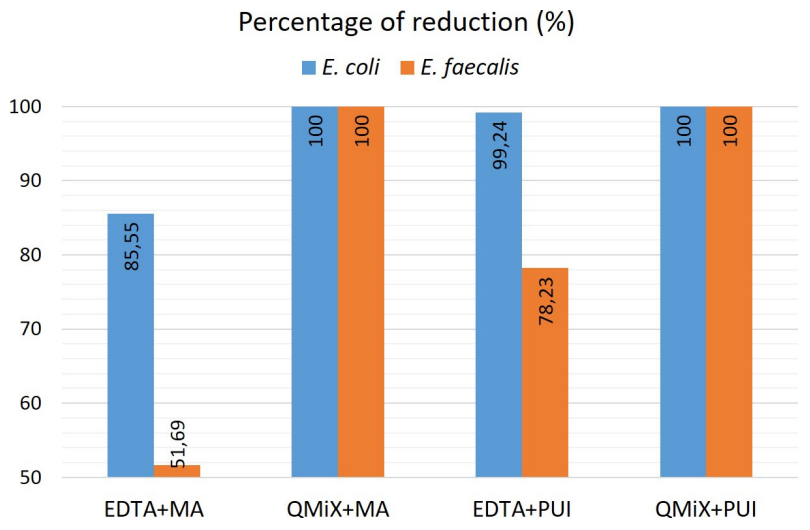

Figure 1. Mean reduction percentage of Escherichia coli and Enterococcus faecalis in root canals after the final irrigation protocols (S3) in relation to post-instrumentation (S2). microorganisms remains inside the root canal and dentinal tubules, especially in areas inaccessible to instruments and conventional irrigation, which can be removed by final irrigation protocols.

According to our results, only the final irrigation with QMiX, regardless of the agitation technique, eradicated $E$. coli and E. faecalis bacteria from the root canal, whereas EDTA was not effective against $E$. faecalis (Table 1). QMiX was introduced on the market in 2012 as a final irrigator to be used for 60 to $90 \mathrm{~s}$ after irrigation with $\mathrm{NaOCl}$ (7). It has both smear layer removal capacity similar to EDTA 17\%, as well as strong and fast acting antibacterial activity due to its chemical composition containing EDTA, CHX and an unspecified detergent (5-7). In this study, QMiX was used for $2 \mathrm{~min}$ in the final irrigation because it was demonstrated that an action time greater than 1 min would be better to eliminate endodontic bacteria (8). In the study by $\mathrm{Ma}$ et al. (7), QMiX was as effective as $6 \% \mathrm{NaOCl}$ in killing $E$. faecalis within root dentin after 1 and 3 min of exposure to these solutions, and has been shown to be superior to $2 \% \mathrm{CHX}, 2 \% \mathrm{NaOCl}, 17 \%$ EDTA, $0.2 \%$ cetrimide and MTAD in different study models $(6,8,17)$, but $2 \% \mathrm{CHX}$ has longer residual antimicrobial activity (up to $36 \mathrm{~h}$ ) (9). Another advantage of $\mathrm{QMiX}$ is due to its chemical design which does not form any potentially carcinogenic precipitate such as those arising from the interaction between EDTA and CHX and between $\mathrm{NaOCl}$ and $\mathrm{CHX}$, and has not been associated with tooth erosion $(7,8)$, which favors its indication as final irrigator. Juric et al. (10) also found a high reduction percentage of $E$. faecalis CFUs by QMiX (99.3\%) when compared it with antimicrobial photodynamic therapy (98.8\%) and Nd: YAG laser (96\%).

Our results were consistent with those of Morgental et al. (8) who did not observe antimicrobial effect of EDTA on E. faecalis. Although EDTA does not exhibit bactericidal

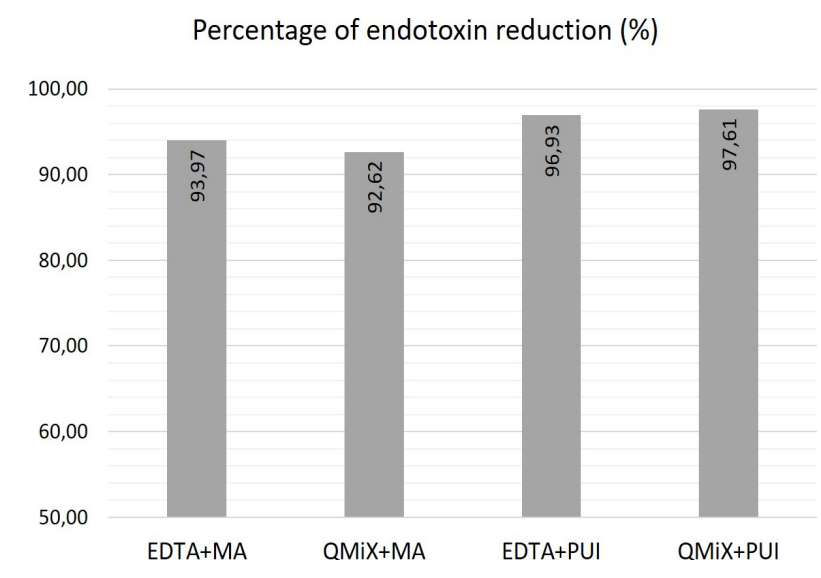

Figure 2. Mean reduction percentage of endotoxin (\%) 7 days after the final irrigation protocols (S4) in relation to the initial sampling (S1). 
action when used alone, it can cause damage to the cell wall of gram-negative bacteria and alter its permeability (18), which may have made it effective against $E$. coli. In turn, E. coli penetrates much less into the dentin tubules than $E$. faecalis and other bacterial species, which may make it more susceptible to irrigating agents (19).

Seven days after chemical-mechanical preparation (S4), there was a significant increase of $E$. coli in all groups (Table 1) in relation to S3, and in the EDTA+MA and EDTA+PUI groups the increase was also significantly higher than the amount found in S2. This was probably due to the fact that these microorganisms survived inside the dentinal tubules, especially in the apical third of the root canal, and were not affected by the antimicrobial action of the final irrigating solutions, which led to the recolonization of the main root canal during the 7 days without intracanal medication (15). On the other hand, no E. faecalis was detected even after 7 days (S4) in the groups treated with QMiX (Table 1), suggesting a complete elimination of this microorganism by this substance.

The use of both EDTA and QMiX chelants is essential for the disorganization of the bacterial biofilm and removal of the smear layer produced during the preparation of the root canal because its presence contributes to the adhesion and colonization of bacteria and endotoxins in the dentin matrix (20). However, the antimicrobial and substantivity properties of chlorhexidine aggregated to QMiX (8) may have been preponderant to prevent bacterial recolonization during the 7 days after treatment. The incorporation of a detergent into the QMiX also favors its action in a larger surface area in the root canal and in a greater depth in the dentinal tubules by reducing its surface tension and increasing its wettability (8). In contrast, 17\% EDTA has high surface tension and low permeability, which limited its antimicrobial effect (9).

When comparing the amount of endotoxin after final irrigation (S3) in relation to post-instrumentation (S2), we can observe that there was a numerical increase, but not significant, in all groups (Table 2). This discrete increase in LPS concentration immediately after final irrigation can be expected because such endotoxins are released upon multiplication and killing of gram-negative bacteria $(15,21)$. In this case, the final irrigation protocols were highly effective in killing $E$. coli (Table 1), generating a large amount of bacterial by-products, but were not as efficient in removing endotoxins immediately after the bacterial death. LPS may irreversibly adhere to the dentin walls, further hindering its removal by the flow of the final irrigating solution, thus, the chelating action may favor its removal (22). In addition, the LPS depth penetration is 4 times greater than gram negative bacteria invasion, as a result of its molecular weight (23). According to Martinho and Gomes (21), clinical symptoms such as palpation pain and percussion sensitivity seem to be more related to endotoxin content in the root canal than to the number of viable bacteria themselves, reinforcing the importance of their effective removal or neutralization, although it is not yet known the minimum amount of endotoxin sufficient to cause such effects.

In our study, teeth that were treated with $\mathrm{QMiX}+\mathrm{PUI}$ (Fig. 2) had a higher percentage of endotoxin reduction (97.61\%), although no protocol alone satisfactorily eliminated LPS from the root canal. Moreover, only in the $\mathrm{QMiX}+\mathrm{PUI}$ group there was a significant reduction of LPS at 7 days in relation to post-instrumentation (Table 2). Since previous studies have shown that $\mathrm{NaOCl}, \mathrm{CHX}$ gel and 17\% EDTA do not have a detoxifying effect against LPS $(2,11,22)$, the association with PUI may contribute to a better action on LPS. Besides that, EDTA and QMiX are potent chelating agents that can affect the endotoxin structure by binding to the calcium present in the lipid $\mathrm{A}$ portion, the bioactive center of the LPSs, preventing them from forming aggregate structures, which facilitates their removal during irrigation, and consequently decreasing their ability to bind to host immune cells and their proinflammatory activity $(11,20)$. Despite EDTA and QMiX have similar chelating effect $(5,6)$, Gründling et al. (11) reported that only QMiX was able to reduce LPS levels in relation to $17 \%$ EDTA and also to $3 \% \mathrm{NaOCl}$ and $2 \% \mathrm{CHX}$. We attributed the efficacy of QMiX and EDTA in removing LPS to the synergistic effect of the ultrasonic activation and not to its chemical performance alone. Furthermore, the presence of surfactants (detergents) may have favored the removal of LPS by QMiX when activated ultrasonically. Our findings were consistent with other studies that observed an increase in the reduction of smear layer (3), bacteria (24) and endodontic toxins (22) when supplementing irrigation with PUI. Ultrasonic activation probably improved the efficacy of the final irrigation solution in the eradication of bacteria and LPS by causing shear stress in bacterial cells by acoustic transmission and collapse of air bubbles that creates vacuum pressure and disorganizes the biofilm and bacterial by-products (25).

In summary, the present research reinforced the findings of previous research that mechanical instrumentation combined with irrigation and aspiration effectively reduces bacteria and endotoxins of root canals $(2,15,20,22)$. In addition, we have shown that final irrigation is equally important to eliminate microorganisms and by-products that have resisted chemical-mechanical preparation. Although there is a continuous search for a disinfection protocol that is capable of eliminating endodontic microorganisms and their endotoxins, total disinfection is impossible due to the anatomical complexity of the root 
canal system. Even so, new experiments with protocols and chemical substances with potential to overcome current results should be developed in order to maximize disinfection of root canals. Clinical trials should be performed to validate our results.

In conclusion, the present study demonstrated that final irrigation with $\mathrm{QMiX}$ associated with manual or passive ultrasonic agitation had superior antibacterial efficacy to EDTA and eliminated $100 \%$ of $E$. coli and E. faecalis strains. QMiX+PUI reduced the initial LPS content by $97.61 \%$ and removed more endotoxins than EDTA+PUI, EDTA+MA and $\mathrm{QMiX}+\mathrm{MA}$.

\section{Resumo}

0 presente estudo objetivou comparar a eficácia do QMiX e do EDTA 17\% associado à irrigação ultrassônica passiva (PUI) ou agitação manual (MA) na redução de $E$. faecalis, E. coli e LPS de canais radiculares. Quarenta dentes humanos unirradiculares foram divididos aleatoriamente em quatro grupos $(n=10)$, de acordo com o protocolo final de irrigação: EDTA+MA, QMiX+MA, EDTA+PUI, QMiX+PUI. Coletas das amostras foram obtidas a partir do conteúdo do canal radicular imediatamente antes do preparo (inicial-S1), após a instrumentação (S2), após o protocolo final de irrigação (S3) e 7 dias após a instrumentação e irrigação final (S4). A eficácia antimicrobiana e o conteúdo de endotoxina foram analisados por procedimento de cultura $(\mathrm{UFC} / \mathrm{mL})$ e ensaio LAL $(\mathrm{EU} / \mathrm{mL})$, respectivamente. Os resultados foram analisados estatisticamente pelo teste de Kruskal-Wallis e Friedman ( $\alpha=5 \%)$.

¿ $\mathrm{OMiX}+\mathrm{MA}$ e $\mathrm{QMiX}+\mathrm{PUI}$ reduziram $100 \%$ das bactérias $E$. coli e $E$. faecalis e ¿ também preveniram a recolonização de $E$. faecalis em S4. 0 EDTA reduziu

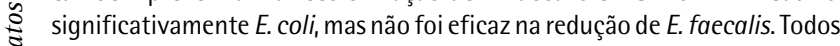
os protocolos reduziram $\mathrm{EU} / \mathrm{mL}$ quando comparados com $\mathrm{S} 1$, no entanto, no vं S4 houve uma redução significativa de $\mathrm{EU} / \mathrm{mL}$ apenas nos grupos $\mathrm{QMiX}+\mathrm{MA}$

«. e QMiX+PUI em relação a S3 e S2, respectivamente. A irrigação final com QMiX associada a MA ou PUI apresentou eficácia antibacteriana superior em relação ao EDTA, eliminando $100 \%$ das cepas de E. coli e E. faecalis. Além disso, QMiX+PUI reduziu $97,61 \%$ do conteúdo inicial de LPS.

\section{Acknowledgements}

This study was supported by CAPES (Coordination of Improvement of Higher Education Personnel) and FAPESP (São Paulo Research Foundation; grant n. 2014/ 25789-9).

\section{References}

1 Cardoso FG, Ferreira NS, Martinho FC, Nascimento GG, Manhães LR, Rocco MA, et al. Correlation between volume of apical periodontitis determined by cone-beam computed tomography analysis and endotoxin levels found in primary root canal infection. J Endod 2015;41:1015-1019.

2 Gomes BPFA, Martinho FC, Vianna ME. Comparison of $2.5 \%$ sodium hypochlorite and $2 \%$ chlorhexidine gel on oral bacterial lipopolysaccharide reduction from primarily infected root canals. J Endod 2009;35:1350-1353.

3 Virdee SS, Seymour DW, Farnell D, Bhamra G, Bhakta S. Efficacy of irrigant activation techniques in removing intracanal smear layer and debris from mature permanent teeth: a systematic review and metaanalysis. Int Endod J 2018;51:605-621.

4 Teixeira CS, Felippe MCS, Felippe WT. The effect of application time of EDTA and $\mathrm{NaOCl}$ on intracanal smear layer removal: an SEM analysis. Int Endod J 2005;38:285-290.

5 Dai L, Khechen K, Khan S, Gillen B, Loushine BA, Wimmer CE, et al. The effect of $\mathrm{OMix}$, an experimental antibacterial root canal irrigant, on removal of canal wall smear layer and debris. J Endod 2011;37:80-84.

6 Stojicic S, Shen Y, Qian W, Johnson B, Haapasalo M. Antibacterial and smear layer removal ability of a novel irrigant, QMiX. Int Endod J 2012;45:363-371.

7 Ma J, Wang Z, Shen Y, Haapasalo M. A new noninvasive model to study the effectiveness of dentin disinfection by using confocal laser scanning microscopy. J Endod 2011;37:1380-1385.

8 Morgental RD, Singh A, Sappal H, Kopper PMP, Vier-Pelisser FV, Peters OA. Dentin inhibits the antibacterial effect of new and conventional endodontic irrigants. J Endod 2013;39:406-410.

9 Zhang R, Chen M, Lu Y, Guo X, Qiao F, Wu L. Antibacterial and residual antimicrobial activities against Enterococcus faecalis biofilm: a comparison between EDTA, chlorhexidine, cetrimide, MTAD and QMix. Sci Rep 2015;5:6-10.

10 Jurič IB, Plečko V, Anić I, Pleško $S$, Jakovljević $S$, Rocca JP, et al. Antimicrobial efficacy of photodynamic therapy, Nd: YAG laser and QMiX solution against Enterococcus faecalis biofilm. Photodiagnosis Photodyn Ther 2016;13:238-243.

11 Gründling GL, Melo TA, Montagner F, Scarparo RK, Vier-Pelisser FV. $\mathrm{QMix}^{\circledR}$ irrigant reduces lipopolysacharide (LPS) levels in an in vitro model. J Appl Oral Sci 2015;23:431-435.

12 Peters OA, Boessler C, Zehnder M. Effect of liquid and paste-type lubricants on torque values during simulated rotary root canal instrumentation. Int Endod J 2005;38:223-229.

13 Ballal NV, Kandian S, Mala K, Bhat KS, Acharya S. Comparison of the efficacy of maleic acid and ethylenediaminetetraacetic acid in smear layer removal from instrumented human root canal: a scanning electron microscopic study. J Endod 2009;35:1573-1576.

14 Niu W, Yoshioka T, Kobayashi C, Suda H. A scanning electron microscopic study of dentinal erosion by final irrigation with EDTA and $\mathrm{NaOCl}$ solutions. Int Endod J 2002;35:934-939.

15 Vianna ME, Horz HP, Conrads G, Zaia AA, Souza-Filho FJ, Gomes BPFA. Effect of root canal procedures on endotoxins and endodontic pathogens. Oral Microbiol Immunol 2007;22:411-418.

16 Martinho FC, Chiesa WM, Zaia AA, Ferraz CC, Almeida JF, Souza-Filho $\mathrm{FJ}$, et al. Comparison of endotoxin levels in previous studies on primary endodontic infections. J Endod 2011;37:163-167.

17 Wong AW, Tsang CS, Zhang S, Li KY, Zhang C, Chu CH. Treatment outcomes of single-visit versus multiple-visit non-surgical endodontic therapy: a randomised clinical trial. BMC Oral Health 2015;15:162.

18 George S, Hamblin MR, Kishena A. Uptake pathways of anionic and cationic photosensitizers into bacteria. Photochem Photobiol Sci 2009;8:788-795.

19 Orstavik D, Haapasalo M. Disinfection by endodontic irrigants and dressing of expirementally infected dentinal tubules. Scand Inst Dent Mater 1990;6:142-149.

20 Martinho FC, Chiesa WM, Marinho AC, Zaia AA, Ferraz CC, Almeida JF, et al. Clinical investigation of the efficacy of chemomechanical preparation with rotary nickel-titanium files for removal of endotoxin from primarily infected root canals. J Endod 2010;36:1766-1769.

21 Martinho FC, Gomes BPFA. Quantification of endotoxins and cultivable bacteria in root canal infection before and after chemomechanical preparation with 2.5\% sodium hypochlorite. J Endod 2008;34:268-272.

22 Herrera DR, Martinho FC, de-Jesus-Soares A, Zaia AA, Ferraz CCR, Almeida JFA, et al. Clinical efficacy of EDTA ultrasonic activation in the reduction of endotoxins and cultivable bacteria. Int Endod J 2017;50:933-940.

23 Berkiten M, Okar I, Berkiten R. In vitro study of the penetration of Streptococcus sanguis and Prevotella intermedia strains into human dentinal tubules. J Endod 2000;26:236-239.

24 Muhammad $\mathrm{OH}$, Chevalier $\mathrm{M}$, Rocca JP, Brulat-Bouchard N, Medioni E. Photodynamic therapy versus ultrasonic irrigation: interaction with endodontic microbial biofilm, an ex vivo study. Photodiagnosis Photodyn Ther 2014;11:171-181.

25 Martin $\mathrm{H}$, Cunningham W. Endosonic endodontics: the ultrasonic synergistic system. Int Dent J 1984;34:198-203.

Received August 17, 2018 Accepted January 21, 2019 